\title{
The difficulty of predicting postoperative acute kidney injury from preoperative clinical data
}

\author{
Daniel T. Engelman, MD, FACS, ${ }^{\mathrm{a}, \mathrm{b}}$ and John A. Kellum, MD, FACP, MCCM
}

\footnotetext{
From the ${ }^{\mathrm{a}}$ Department of Surgery, Baystate Medical Center, Springfield, Mass; ${ }^{\mathrm{b}}$ University of Massachusetts Medical School-Baystate, Springfield, Mass; and ${ }^{c}$ Department of Critical Care Medicine, University of Pittsburgh, School of Medicine, Pittsburgh, Pa.

Disclosures: D.T.E. is a speaker for Mallinkrodt Pharmaceutical, a consultant for Astute Medical, and is on the Medical Advisory Board for Pavillion Medical. J.A.K. reports grant support and consulting fees from Astute Medical and Bioporto.

Received for publication March 19, 2018; accepted for publication March 22, 2018; available ahead of print April $14,2018$.

Address for reprints: Daniel T. Engelman, MD, FACS, 759 Chestnut St, Springfield, MA 01199 (E-mail: Daniel. Engelman@baystatehealth.org).

J Thorac Cardiovasc Surg 2018;156:1124

$0022-5223 / \$ 36.00$

Copyright (C) 2018 by The American Association for Thoracic Surgery

https://doi.org/10.1016/j.jtcvs.2018.03.071
}

Acute kidney injury (AKI) is associated with significant morbidity and mortality after cardiac surgery. ${ }^{1,2}$ Recent studies have demonstrated the use of early postoperative urinary biomarkers and selected goal-directed therapy to reduce this incidence in patients with documented kidney stress. ${ }^{3}$ However, little is known concerning the use of markers for preoperative risk assessment. If the risk for AKI could accurately be assessed before surgery, it would open the door to multiple areas of decision-making including the timing of surgery, appropriate intraoperative management, and potentially earlier postoperative interventions.

In this article, Lobdell and associates ${ }^{4}$ have shown that predicting AKI from preoperative data is challenging. By using the Northern New England Cardiovascular Disease Study Group data from 8 hospitals, 1690 patients were sampled undergoing isolated coronary artery bypass graft surgery. Blood samples were collected before incision. The authors found that $35 \%$ of the patients developed AKI using the Acute Kidney Injury Network criteria. The authors developed a clinical risk model using patient characteristics, including medical history and physiologic and laboratory variables. Their model had rather modest performance (area under the curve, 0.66). They also measured some novel biomarkers including soluble serum ST2, a member of the interleukin-1 receptor family of proteins, and N-terminal pro-B-type natriuretic peptide. Patients in the highest tercile of ST2 had twice the odds of developing stage II or stage III AKI compared with stage I, demonstrating a strong biologic signal. Unfortunately, neither biomarker improved discrimination much in the lower ranges (area under the curve, 0.72 and 0.68 , respectively).

Nonetheless, this article is the first demonstration of ST2 as a potential predictor of AKI among patients undergoing coronary artery bypass in a large cardiac surgical cohort.

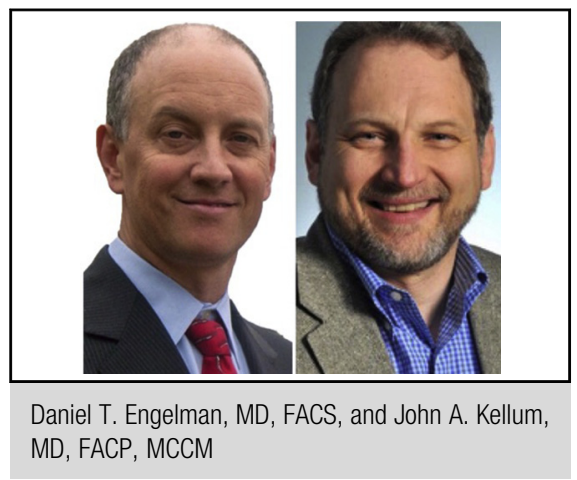

\section{Central Message}

This is the first demonstration of ST2 as a preoperative predictor of AKI in patients undergoing cardiac surgery. This may facilitate earlier coordinated efforts to prevent short- and longterm morbidity and mortality.

See Article page 1114 .
The concept of preoperative biomarker-guided risk prediction to prevent $\mathrm{AKI}$ is attractive. It could be used to appropriately delay elective or urgent planned surgeries; initiate higher cardiopulmonary bypass nadir hematocrits, flows, or pressures; and avoid the use of nephrotoxic medications. Postoperatively, these patients may require greater attention to goal-directed therapy and cardiac output optimization. The only other test that addresses this need is the so-called renal stress-test measuring glomerular reserve. $^{5}$ Future work to discover biomarkers or biomarker combinations, perhaps including ST2, are therefore of great interest to cardiac surgeons.

\section{References}

1. Hobson CE, Yavas S, Segal MS, Schold JD, Tribble CG, Layon AJ, et al. Acute kidney injury is associated with increased long-term mortality after cardiothoracic surgery. Circulation. 2009;119:2444-53.

2. Engelman DT, Kellum JA. Should urinary biomarkers be a standard component of evaluation after cardiac surgery? J Thorac Cardiovasc Surg. 2018 [Epub ahead of print].

3. Meersch M, Schmidt C, Hoffmeier A, Van Aken H, Wempe C, Gerss J, et al. Prevention of cardiac surgery-associated AKI by implementing the KDIGO guidelines in high risk patients identified by biomarkers: the PrevAKI randomized controlled trial. Intensive Care Med. 2017;43:1551-61.

4. Lobdell K, Parker DM, Likosky DS, Rezaee M, von Ballmoos MW, Alam SS, et al. Preoperative serum ST2 level predicts acute kidney injury after adult cardiac surgery. J Thorac Cardiovasc Surg. 2018;156:1114-23.e2.

5. Husain-Syed F, Ferrari F, Sharma A, Danesi TH, Bezerra P, Lopez-Giacoman S, et al. Preoperative renal functional reserve predicts risk of acute kidney injury after cardiac operation. Ann Thorac Surg. 2018;105:1094-101. 